\title{
EXPERIENCES OF SUPERNUMERARY STATUS AND THE HIDDEN CURRICULUM IN NURSING: A NEW TWIST IN THE THEORY- PRACTICE GAP?
}

\author{
Abstract \\ Aims: to increase understanding about how student nurses' experiences of supernumerary status \\ which are embedded within the hidden curriculum in clinical practice contribute to the theory- \\ practice gap in nursing. \\ Background: current literature suggests that the hidden curriculum exists in many professional \\ curricula and that it functions to socialise students into professional behaviours and practice.
}

However, in nursing, there is a gap in our understanding of how these socialisation processes have been influenced by supernumerary status and what forms the hidden curriculum might take currently in clinical practice.

Design: an ethnographic case study design.

Method: data were collected in four sites using fieldwork in clinical practice as well as interviews with students, mentors and key stakeholders and an on-line survey of student bodies in four universities. The findings discussed in this paper are drawn from the qualitative fieldwork and interviews and were analysed thematically.

Results: the findings suggest supernumerary status is an important aspect of the hidden curriculum in clinical learning for nursing students; that students are expected by trained staff to work while they learn, and that on registration, they expect and are expected to be competent to work immediately as registered nurses. These expectations are at odds with those of academic nurses and contribute to a theory-practice gap for student nurses. These expectations form part of the hidden curriculum which shapes the clinical context and students have to learn to negotiate their status as supernumerary students in practice to meet these expectations. Negotiation includes resistance to these expectations.

Conclusions: Consequently, students have to learn within a disintegrated learning context where opposing values of learning exist.

Relevance for clinical practice: to re-integrate student nurses' learning, educators in universities and clinical practice have to understand how the hidden curriculum and expectations around supernumerary status among trained staff affect learning for students.

\author{
Key words \\ Hidden curriculum \\ Clinical learning \\ Student nurses \\ Mentors \\ Supernumerary status \\ Theory-practice gap
}




\section{Introduction}

The hidden curriculum has been identified in many professional curricula including the health professions (Cook 1991, Davies 1993, Mayson \& Hayward 1997, Hafferty 1998; Aled 2007). It is via the hidden curriculum that students are socialised into professional behaviours and practice. These socialisation processes are influenced by the roles of experienced professionals who act as practice teachers, mentors and role models for students. However, in nursing, there is a gap in the profession's understanding of how these socialisation processes have been influenced by supernumerary status (if they have) and what forms the hidden curriculum might take currently in clinical practice. This paper aims to fill that gap using data from a national study to analyse student nurses' experiences of, and trained staff's attitudes to supernumerary status. Nursing students work in a supernumerary capacity, that is, they are not counted in the rostered numbers of ward staff in the clinical areas and have to work under the supervision of trained nurses, ideally their mentors.

I argue that to be an effective learner, the student nurse has to negotiate their position within the ward team and with their mentor by finding out how clinical staff in each placement view supernumerary status and act according to those expectations. These expectations are frequently not overt and are contained within the hidden curriculum and negotiation includes resisting these expectations.

\section{Background}

The hidden curriculum refers to the "processes, pressures and constraints which fall outside...the formal curriculum, and which are often unarticulated or unexplored" (Cribb \& Bignold 1999 p.24). The hidden curriculum is revealed in the language and strategies that teachers/professional mentors or role models use in classroom or lecture theatres and practice settings (Conroy 2001); some of these implicit messages and signals may be non-verbal. Lempp \& Seale (2004), citing others (Cribb \& Bignold 1999, Hafferty 2000, Bloom 1972, Assor \& Gordon 1987) have argued that the hidden curriculum in professional education is especially important due to the amounts of time spent exposed to the predominant professional culture in practice as opposed to time spent in the academic setting.

In the international literature, the term hidden curriculum has been discussed in relation to globalisation and the transfer of knowledge across countries which have very different traditions of curriculum studies and educational systems (Pinar 2003). Pinar discusses how in some countries, notably Japan and Africa, curricula have had western values embedded within them without critical discussion of whether these values meet traditional indigenous values. The term nevertheless, seems to have international currency across disciplines and time (Varpalotai 1987, Perez Morales et al 2002, Egea-Kuehne 2003).

As Spouse and Redfern (2000) assert, there is a fine line between the tangible and intangible aspects of the curriculum. Hargreaves (1980) has suggested that these intangible aspects are in fact known and obvious to everyone involved; the term hidden curriculum is often inappropriate and he suggests a better term to be paracurriculum, that which is taught and learnt alongside the formal curriculum.

In the UK, mentors are instrumental in socialising students into professional behaviours and practice in their roles as practice teachers and role models (Davies 1993, Spouse 1996, 1998b, Field 2004, Hall 2006, Brammer 2006). Brammer (2006) suggests that the trained nurse may act as a 'gatekeeper' (in a positive or negative sense) to learning and the integration of theory and practice in the clinical learning environment while Gray \& Smith (2000) argue that students may perceive the assessment role to interfere with their relationship with mentors and their 
socialisation into practice. Having a mentor who has realistic expectations and knows the curriculum, is important in creating a good learning experience for students (Gray \& Smith 1999). However, the mentor's contribution to student nurse learning may not always be beneficial although many students learn from negative experiences of being mentored (Pearcey \& Elliot 2004). This negative effect maynot be down to the individual poor mentor but the wider, political context in whichlearning takes place. Benson \& Latter (1998) argue that the political climate in which students learn in practice shapes the theory-practice relationship. Part of this relationship and political climate is the hierarchy between those who have knowledge and students who need to learn (Cahill 1996). The formal and hidden curricula are thereby constructed in practice as opposing experiences which lack integration (Field 2004) for both students and their mentors. Equally having a mentor who is supportive is essential in socialising the student into the emotional challenges of nursing as experiences in practice very often "challenge and threaten normal human activities" (Cribb \& Bignold 1999 p.198). One way such challenges are survived is through clinical role modeling, which socialises neophytes into professional practice (Davies 1993; Donaldson \& Carter 2005). Clinical role modeling importantly, also validates students' experiences in practice which the university fails to do (Spouse 1998a, 1998b, Cribb \& Bignold 1999).

\section{Methods}

The aim of the study was to explore who is responsible for the leadership of student nurse learning in clinical practice given the changes in nursing leadership roles at ward management level and the move of nursing education to universities. The necessary National Research Ethics Service approvals and local NHS Trust Research and Development approvals were obtained.

It was an ethnographic case study design (Burawoy 1991) with two stages. Stage 1 incorporated a literature study and 10 stakeholder interviews with leaders in nurse education (Allan et al 2007). In stage 2, four ethnographic case studies of leadership for clinical learning were undertaken in four sites across England which were selected from higher education institutions (HEIs) that offered diploma and degree level education for pre-registration nursing. Data were collected from the higher education institutions as well as a range of clinical practice settings in acute NHS Trusts where students were allocated for their clinical experience. Data were collected using an online survey, observational participation in the clinical areas and documentary analysis of the written curricula in each HEI. The purpose of three data collection methods was to integrate the different sources of data and present as integrated analysis (Moran Ellis et al 2006).

The data on which this paper is based draws on the fieldwork in stage 2. Each period of fieldwork lasted 5 days in each site; periods of observation were undertaken in a range of clinical settings to observe the student experience of the learning environment and informally interview student nurses and their mentors and managers through working alongside them. The settings included accident and emergency departments, medical and surgical wards; each observation period started at the beginning of a morning shift to observe handover and allocation of nursing duties. The researcher spent time observing and not participating when students were working with their mentors and also worked with students, engaging them and their mentors and the staff working the shift in informal interviews and using her observations as probes to explore their thoughts about student learning, leadership roles in the new NHS and clinical leadership in general. In total, she informally interviewed and worked with four second year, seven third year and two first year student nurses (13 in total).

Formal interviews and focus groups across the sites were undertaken with trained nurses involved in student nurses' learning using a prepared interview schedule based on the conceptual 
framework developed from the literature review in Stage 1. Formal interviews and focus groups with the staff are summarised in Table 1. Of interest is that the average age of the ward managers was 42 which meant that their experience of students included both pre and post curricula changes in the 1980s and 1990s and they had a wealth of knowledge on which to draw in the interviews.

Table 1: Summary table of staff interviewed across four fieldwork sites

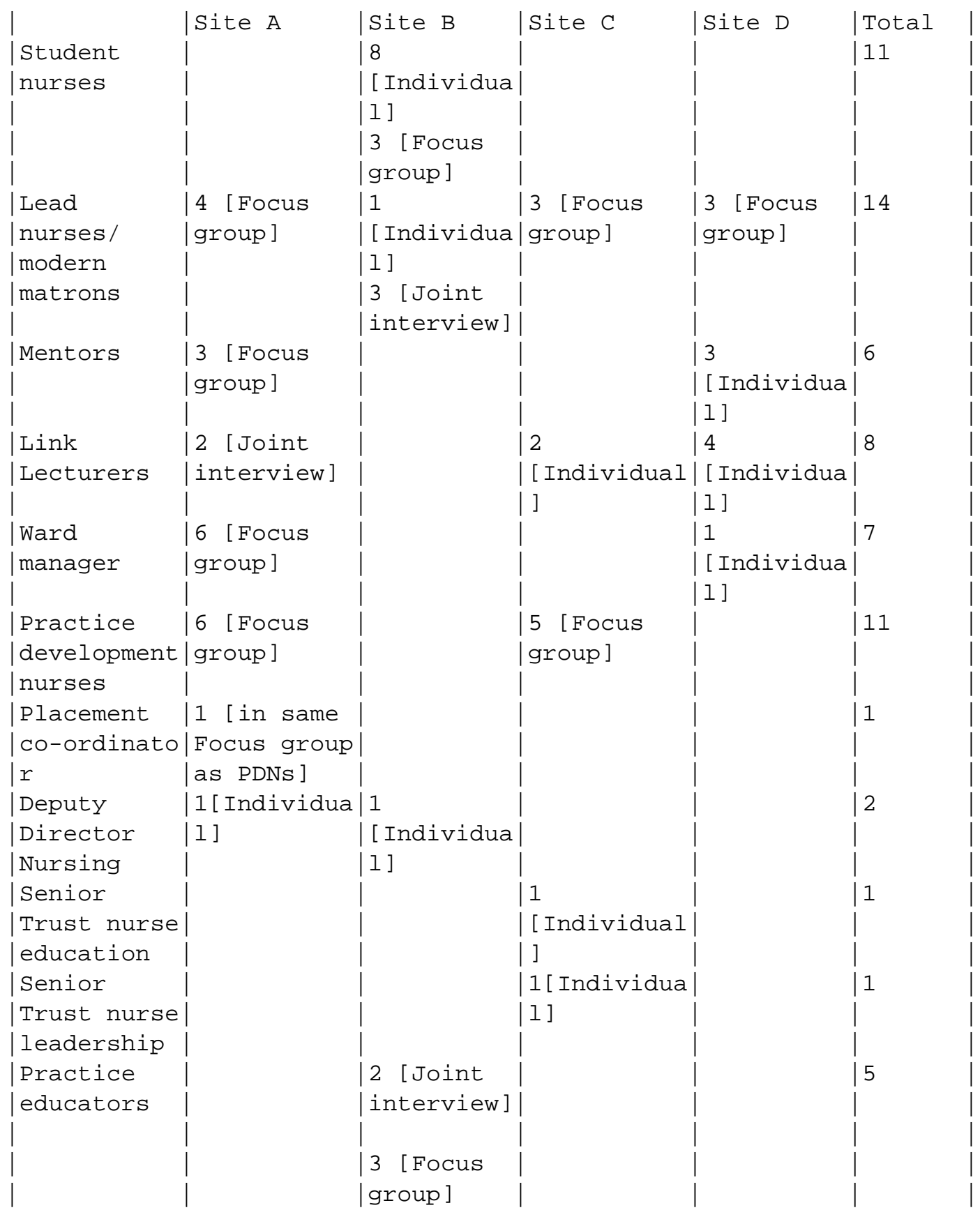

\section{Results: negotiating supernumerary status}

The findings suggest that supernumerary status is devalued in practice; mentors' and senior nurses' expectations for students to work as members of a team rather than remain supernumerary indicate that their motivations for supporting learning reflect different values to those espoused in the university. Understanding and negotiating ward staff's expectations of supernumerary status appear to be integral to having a successful clinical placement and in this way, student nurses are 
socialised into the norms of practice. Resisting expectations is a form of negotiation chosen by some students as they actively plan how to achieve their learning objectives. The ward staff's expectations show students that an opposing set of values of learning exist to those they have previously been exposed to at university. Two findings are used to illustrate our argument. Supernumerary status prevents learning

Trained nurses felt that supernumerary status removed students from learning through doing and that being supernumerary and therefore not working and learning has implications for their ability to work competently on registration; in other words, being supernumerary diminished their ability to perform in the future as qualified nurses. A quote from a focus group discussion with ward managers illustrates this view:

"The impression I get now with students, when they qualify, that's when they start to learn. They don't really learn very much about nursing at all while they're students. In some ways, the first newly qualified band $5 \mathrm{~s}$ seem like second or third year student nurses of previous years"

It is interesting that these ward managers did not appear to believe that learning continued after registration. As Chambers (2007) argues, the NHS expects nurses to be ready to assume a full working load on qualifying as registered nurses. Ward managers also criticised supernumerary status because they felt that it affected students' learning if ward areas were busy and mentors and co-mentors were unable to work with them as being supernumerary meant that independent working, and therefore learning through working, was unacceptable. In the following quote from the same focus group, a ward manager observes that the business of clinical areas means that students can become lost and aimless:

"It's quite difficult sometimes, especially when they're supernumerary and it's extremely busy and you have to tell them 'If you're lost, please go back to the nurses' station' because they can be wandering around quite aimlessly"

A manager in another focus group felt that students were not prepared for the business of the ward and therefore that there would be times when they might feel they were not learning:

"I don't think students are prepared for [the changing situation on the wards] and I don't think college prepares them before they come in. They've expectations of learning all this whereas it's really quick and fast and I think they need to be prepared more for the environment they're coming into"

However, students were not always affected by the busy nature of the wards if their mentor was there to support them in a general capacity although in this quote the student doesn't reflect on the quality of her learning without supervision:

“Although I'm supernumerary, I'm kept very busy. I don't feel unsafe just very busy. Brenda's always around (the student's mentor)".

Other students were affected by being busy as the researcher's field notes reveal:

Surgery "Coffee break with student nurse whose 1st placement was a care home. HA asked what she'd learnt in the care home. She said immediately 'confidence' as she'd never done care work before and she felt she did 'all that there'; she'd learnt confidence in meeting people, making relationships with them, getting to know them. And in surgery, these skills had given her confidence (again!) to cope with the faster pace and higher turnover. Surgery is "Very busy, short stay, patient turnover is high - have to be out in 23 hours. [I have] to work in a bay with 6 patients on $1 / 2$ hourly observations was difficult. She asked me and then answered her own question, 'How do you keep up? You learn to do things faster'", 
Ward managers and students felt that working on busy wards was stressful, and observed that students were not prepared for the busy clinical areas where supernumerary status could prevent students from working with patients with their mentors and therefore from learning. This led to observations from ward managers that students were "aimless" and feelings among some students that they felt "coping with the fast pace was difficult".

Integrating theory and practice: balancing safe and unsafe practice

Supernumerary status was not observed to be a standard process across the sites or within the same site; it varied between individual mentoring relationships and clinical areas. The consequence of the lack of standardisation of supernumerary status meant that students had to learn in each placement at different stages of their programme what was expected of them by their mentors. This led to them feeling safe at times and unsafe at others.

During observation periods, a variety of ways were observed in which students worked in the clinical areas with varying degrees of supervision. For example, junior nurses working with trained staff very closely as described in the following extract from her field notes:

(17/01/07 Site D day surgery, morning shift) "HA came onto the ward and the staff nurse and student ( $2^{\text {nd }}$ year) are arranging shifts to work together. Staff nurse walked off from the station saying for the student to follow her which she didn't immediately. Staff nurse gestured 'come on' like there was a lead tying the student to her. They both laughed".

While this may seem patronising, this mentor explained later to me that ensuring students felt safe but at the same time gained competencies and confidence was very important to her.

The balance required between needing to learn and being safe was raised by the students during a coffee beak in a surgical ward. A male $3^{\text {rd }}$ year student explained that:

"My uncle says in his second year he was in charge of wards and was responsible. But it had to change. You have to be accountable for safe care and you can't just do things to patients".

At the same time, this student recognised that being safe and accountable had left him feeling deskilled: "We've been out of practice for a year during our second year and it felt very strange coming back". He felt that on this ward (a mixed surgical ward) they were given responsibility as $3^{\text {rd }}$ years and expected to work as part of the team. This was different to other wards where they had been junior and the senior students were generally given this preferential treatment. Here, as a third year, he was treated preferentially and his mentor allowed him to check intravenous (IV) drugs, run through IV lines, change IV lines all under supervision. And he appreciated that, as he would have to do those tasks when qualified, he wanted them "under his belt" before then. In a contrasting example from the researcher's field notes, a $3^{\text {rd }}$ year student was observed as working unsupported by trained staff on a busy medical ward one morning shift:

(23/01/07 Site D mixed surgical ward, morning shift) "Staff nurse and student allocated a bay and a transfer to the bay from side room; staff nurse went straight away to do drugs asking student to move patient (very sick man) with healthcare assistant (HCA). Man needed to change to $40 \%$ oxygen $\left(\mathrm{O}_{2}\right)$ from nasal cannula; student went to fetch mask. Came back with no tubing to attach mask to $\mathrm{O}_{2}$; went to find some; came back with wrong tubing; came back with correct tubing and then started fitting mask and tubing. Hadn't done so before, neither had HCA. There was a degree of fluster and patient got more breathless; HCA suggested turning up $\mathrm{O}_{2}$. Student went to ask sister who said 'yes' and came back and turned up $\mathrm{O}_{2}$. HA asked student if she felt okay and understood the reason for turning up $\mathrm{O}_{2}$. She said 'no'; HA explained rationale. This went on for some time before the patient was successfully settled in his new bed; the staff nurse did not appear to supervise the student with a very sick patient 
neither did the sister."

Now while this experience may have involved some learning, it was not clear to the researcher how the student was facilitated to process any learning for transfer to the next acute clinical situation or indeed to feel safe.[1]

Negotiating supernumerary status at handover

Supernumerary status was considered at some allocations at the beginning of shifts where ward managers were observed at handover allocating students according to their learning needs as the following extracts from field notes demonstrate:

(28/02/07 Site C haemato-oncology morning shift) "Sister organised work, everyone hung around the desk as she looked at the patient dependency, the staff and students. Asked students what they wanted to do, whether their mentors were on and knew one $3^{\text {rd }}$ year had a drugs assessment. When I was introduced after handover, she reallocated the students to include me".

And at other handovers in other areas, allocation of students to mentors was not so well organised as in this extract from field notes:

(26/02/07 Site C gynae-oncology morning shift) "Morning shift had handover; I waited for the ward manager to come out of the office. She did, then staff nurses, then two students trailing behind; allocation already done. Students look hesitant but then started breakfasts. I then introduced myself and was told to go and find the students. Later that shift while having coffee with these students, the $3^{\text {rd }}$ year student was angry about what had happened at the start of the shift 'You saw what happened? - We just sorted it out - the other student is pregnant so I took the heavy side. The staff nurses were already busy on the phone so we had to do the work, decide what to do. No-one supervises you." "

Students managed this negotiation through taking stock and assessing the handover to see whether the staff took their learning needs into consideration as the $3^{\text {rd }}$ year student did in the above extract. Another $3^{\text {rd }}$ year student described her negotiation skills explicitly in the following extract from field notes:

(5/01/07 Site D A\&E morning shift) "Very slow start to shift with mentor appearing slow to ask students what they needed to do or indeed identifying them as students who needed to work with mentors if present - the student working with me (HA) said to me later 'I wait to see - is she going to sort me out? Obviously not! - Then I decide what I want to do and who to be with'."

But other students found this allocation difficult and did not know how to negotiate so as to ensure they worked with their mentors as described in this extract:

(15/01/07 Site D A\&E morning shift) "At handover, sister gave out areas of A\&E to different staff - then went through students - 6 student nurses - sister didn't ask who had worked with their mentor, who was mentoring whom, or who needed to learn what. Allocated students to three or four mentors randomly. My student said her mentor was working in 'majors' (major injuries) and she was in 'minors' (minor injuries) with other student nurse; he couldn't take both so my student volunteered to go to 'minors' thinking that she wouldn't argue to get to work with her mentor that shift even though she hadn't worked with him yet during this placement."

Negotiating supernumerary status successfully was important to students because it affected feeling part of the team which was especially important for the $3^{\text {rd }}$ year students I worked with as this extract from field notes shows:

(17/01/07 Site D day surgery morning shift; $3^{\text {rd }}$ year, older, female, part-time student) "At 
coffee, student described how she felt they were told to be assertive and self-empowered in college and to be agents of change yet the NHS and nursing was hierarchical and bullying and she said 'I feel like I' $m$ in the playground again. On ICU, nobody said goodbye to me when I left, too busy doing internet shopping, obsessing about off duty and character assassination of anyone coming into the unit.' She felt that staff referred to the students as 'the student' and staff didn't bother to learn their names; rarely felt part of the team. She used the word 'burden' to describe the mentoring relationship in the clinical areas".

\section{Discussion}

Negotiating expectations around supernumerary status is a new aspect of the hidden curriculum not previously described in the literature which shows a failure by education and practice to integrate theory and practice. Equally, students found their supernumerary status problematic if they were given too much responsibility for care delivery; and unable to achieve their learning outcomes if they were not given sufficient hands on experience.

The notion of negotiation emerged as a way of understanding this problematic because, despite the changes to nurse education over the last 20 years, learning is expected to occur through delivering hands on care rather than through observing or taking on peripheral roles (Spouse 1998a). Supernumerary status was not viewed as legitimate in the data. Senior nurses continue to expect that on registering students will be competent and be able to work as a competent trained nurse without any period of preceptorship. This resonates with a key statement made in the literature that the NHS was a workforce orientated system rather than a learning orientated system (Melia 2005). Essentially, students are still expected to provide labour and on registration are expected to be able to work immediately as fully competent, registered nurses. Supernumerary status is a reality in the curriculum not in the wards yet does not form part of the formal curriculum so that students can be prepared for practice. Central to the role of mentors in the hidden curriculum are mentors' motivations to teach as well as their expectations of students (Gray \& Smith 1999, Watson 1999) and their attitudes to the integration of theory and practice (Cook 1991, Ferguson \& Jinks 1994, Fealy 2001).

It is the lack of integration of theory and practice as well as mentors' motivation to teach and their expectations of students that shapes the hidden curriculum which in turn forms the context in which students have to learn to negotiate their status as supernumerary students in practice. Students have to learn within a disintegrated learning context in which opposing values of learning exist.

Students learnt to negotiate their way around their supernumerary status and take control of their learning. These expectations and the negotiation undertaken by students led to a disintegration of theory and practice between the espoused values of the university regarding supernumerary status and the espoused values of practice. Sadly, it seemed as if students learned despite the structures rather than because of them. Students are proactive in constructing learning opportunities and the mentor does not hold the only key to learning in clinical areas as our data show (Nolan 1998, Brammer 2006). Understanding the strategies that students use to draw out learning opportunities in clinical areas when mentors might be gatekeeping and not facilitating access is useful in identifying active learning and facilitating such strategies in preparing students for practice areas. Students desire to fit in, and want to be accepted by their mentors (Brammer 2006, Lofmark \& Wikblad 2001). Brammer argues that negative experiences do not always reduce learning as some learning can come out of negative experiences; but when learning is negative and the student becomes demoralised, the focus on learning is lost as the feelings become paramount and interfere with learning (Brammer 2006). This was illustrated in the last quote in this paper. 
Spouse (1998b) suggests that students learn effectively through legitimate peripheral participation in a community of practice and this desire seems to be close to what the $3^{\text {rd }}$ years were aspiring to in our data; they desired to become members of the nursing teams but felt that they were not accepted. The findings suggest that this is because their participation as observers was not valued and that the mentors in the study felt that supernumerary status did not equip students with skills to become members until they worked as qualified nurses. What was missing from the mentorstudent relationship was sponsorship which Spouse argues is essential if students are to learn in professional practice settings. Sponsorship means students are taken under a more experienced nurse's wing and granted access to learning through participating in nursing. The data shows that students recognised that this was valued by their mentors and negotiated their way out of supernumerary status to try to achieve this sponsorship.

\section{Conclusions}

It may be that in different health systems with different learning and workforce agendas, students are able to manage their learning with less difficulty and the hidden curriculum is not so influenced by expectations that students will work rather than observe or participate in a supernumerary way. This form of learning may be legitimate. However in the UK context, there is evidence that this approach to learning is not legitimate and leads to a disintegrated learning for students.

This disintegrated learning is located in practice knowledge which runs alongside formal, university knowledge. It is well known practice knowledge but unacknowledged in university; to paraphrase Hargreaves (1980 p.126) 'From whom is the hidden curriculum hidden?' Far from being hidden, this is explicit knowledge expressed in action by ward staff and mentors in practice and might be better known as the para-curriculum.

\section{Relevance for clinical practice}

However this analysis merely leaves the paracurriculum unchallenged and the student stuck in the difficult position of negotiating supernumerary status and trying to make sense of the disintegration of theory and practice. As Hargreaves (1980) suggest this position eventually leads to the destruction of a love of learning. As the $3^{\text {rd }}$ year student nurse said above, being told as a student to be self-empowered and an agent of change is unrealistic; there needs to dialogue between practice and academia for change to take place. Students' experiences of supernumerary status as an aspect of the hidden curriculum is a further demonstration of the theory-practice gap created on both sides of the so-called 50-50 curriculum and one that both practice and nurse educators need to challenge to build a truly effective 50-50 curriculum and partnership in clinical learning.

\section{Conflict of Interest and Source of Funding}

There is no conflict of interest to declare. This work was funded by the General Nursing Council Trust of England and Wales.

\section{Acknowledgements}

Acknowledgements to the participants in this research and to our colleagues Alison Rhodes and Liz Rockingham for their comments on this paper.

\section{Contribution}

Study Design (HA, PS, MoD)

Data Collection and Analysis (HA, PS, MoD) 
Manuscript Preparation (HA)

\section{References}

Aled J (2007) Putting practice einto teaching: an exploratorystudy of nursing udnergraduates' interpersonal skills and the effects of using empirical data as a teaching and learning resource. Journal of Clinical Nursing 16(12), 2297-2307

Allan H T, Smith P A \& Lorentzon M (2007) Leadership for learning: a literature study of leadership for learning in clinical practice. Journal Nursing Management 16, 545-555

Andrews M \& Wallis M (1999) Mentorship in nursing: a literature review. Journal of Advanced Nursing 29 (1), 201-207

Assor A \& Gordon D (1987). The implicit learning theory of hidden curriculum research. Journal of Curriculum Studies 19(4), 329-39

Benner P, Tanner C A \& Chesla C A (1996) Expertise in nursing practice: caring, clinical judgment and ethics. Springer: Cambridge, Massachusetts

Benson A \& Latter S (1998) Implementing health promoting nursing: the integration of interpersonal skills and health promotion. Journal of Advanced Nursing 27, 100-107

Bloom S W (1972) Innocence in education. School Review 80, 333-352

Bowles B \& Gintis H. (1976) Schooling in Capitalist America. Routledge \& Kegan Paul: London Brammer J D (2006) RN as gatekeeper: student understanding of the RN buddy role in clinical practice experience. Nurse Education Today 26, 697-704

Burawoy, M. (1991) Ethnography unbound, power and resistance in the modern metropolis, CA: University of California

Cahill H A (1996) A qualitative analysis of student nurses' experiences of mentorship. Journal of Advanced Nursing 24(4), 791-799

Chambers, D. 2007. Is the modern NHS fit for nursing students? British Journal of Nursing 16(2),74-75

Cook S (1991) Mind the theory-practice gap in nursing. Journal of Advanced Nursing. 16(12), 1462-1469

Conroy S A (2001) Moral inclinations of medical, nursing, and physiotherapy students.

Unpublished doctoral dissertation, University of Oxford: Oxford

Cribb A \& Bignold S (1999) Towards the reflexive medical school: the hidden curriculum and medical education research. Studies in Higher Education 24, 195-209

Davies E (1993) Clinical role modeling: uncovering hidden knowledge. Journal of Advanced Nursing. 18(4), 627-636

Field D (2004) Moving from novice to expert - the value of learning in clinical practice: a literature review. Nurse Education Today 24, 560-565

Donaldson J H \& Carter D (2005) The value of role modeling: perceptions of undergraduate and diploma nursing (adult) students. Nurse Education Today 5, 353-359

Egea-Kuehne D (2003) Understanding curriculum in France: a multifaceted approach to thinking education. In International Handbook of Curriculum Research. (editor) Pinar, W. F. L Erlbaum Associates: New York. pp.329-366

Fealy G M (1999) The theory-practice relationship in nursing: the practitioners' perspective. Journal of Advanced Nursing 30(1), 74-82

Ferguson K E \& Jinks A (1994) Integrating what is taught with what is practiced in the nursing curriculum: a multi-method dimensional model. Journal of Advanced Nursing. 20(4), 687-695 Field D (2004) Moving from novice to expert - the value of learning in clinical practice: a 
literature review. Nurse Education Today 24, 560-565

Gray M A \& Smith L N (2000) The qualities of an effective mentor from the student nurse's perspective: findings from a longitudinal qualitative study. Journal of Advanced Nursing 32(6), $1542-1549$

Hafferty F W (2000) Reconfiguring the sociology of medical education: emerging topics and pressing issues. In: Bird F, Conrad P, Fremont A M (editors) handbook of Medical Sociology $5^{\text {th }}$ edition. New York: Prentice Hall., 238-256

Hall A. (2006) Mentorship in the community. Journal Community Nursing 20(7), 2-6

Hargreaves, D. 1980. Power and the paracurriculum. In Finch A \& Scrimshaw P (editors)

Standards, schooling and education. Buckingham: Open University. pp. 126-137

Lauder W, Sharkey S \& Reed S (2003) The development of family health nurses and family nurse practitioners in remote and rural Australia Australian Family Physician 32(9), 750-2.

Lempp H \& Seale C (2004) The hidden curriculum in undergraduate medical education:

qualitative study of medical students' perceptions of teaching. British Medical Journal 329, 770773

Lofmark A \& Wikblad K (2001) Facilitating and obstructing factors for development of learning in clinical practice: a student perspective. Journal of Advanced Nursing 34(1), 43-50

Mayson J \& Hayward W (1997) Learning to be a nurse: the contribution of the hidden curriculum in the clinical setting. Nursing Praxis in New Zealand. 12(2), 16-22

Melia K (2006) R000271191 - Nursing in the new NHS: a sociological analysis of learning and working.

www.esrc.ac.uk/ESRCInfoCentre/Plain_English_Summaries/LLH/health_wellbeing/index413.

Access 14/11/06

Midgley K (2006) Pre-registration student nurses', perceptions of the hospital-learning environment during clinical placement. Nurse Education Today 26, 338-345

Moran-Ellis J, Alexander VD, Cronin A \& Dickinson M (2006) Triangulation and integration: processes, claims and implications. Qualitative Research 6(1), 45-59

Nursing and Midwifery Council (2004) Project 2000 Papers consisting of Counting the Costs (Feb 1987); the Final Proposals (Feb 1987). www.nmc-uk.org/nmc/main/search/. Access 14/11/06

Nursing and Midwifery Council (2005) Circular 20 Update on the overseas nurses programme. www.nmc-uk.org/nmc/main/search/. Access 14/11/06

Nursing and Midwifery Council (2008) Standards to support learning and assessment in practice.

NMC standards for mentors, practice teachers and teachers. $2^{\text {nd }}$ edition. London: NMC

Pearcey P A \& Elliott B E (2004) Student impressions of clinical nursing. Nurse Education Today 24, 382-397

Perez Morales A, Barallobre Filiquiera A, Cuadrado Martin A, Cuadri Duque M J, Jara Fernandez F J, Gonzalez Ruiz A, Perez-Minayo M T \& Tirado Barragan A (2002) Personal qualities that firstyear nursing students consider essential for the nursing profession. [Spanish] Enfermeria Clinica 12(3), 109-116

Pinar W F (2003). International Handbook of Curriculum Research. (editor) L Erlbaum Asscoiates: New York

Shields M A \& Ward M (2001) Improving nurse retention in the National Health Service in England: the impact of job satisfaction on intentions to quit. Journal of Health Economics 20, 677701

Smith P \& Gray B (2001) Reassessing the concept of emotional labour in student nurse education: role of link lecturers and mentors in a time of change. Nurse Education Today 21, 230-237 
Spouse J (1996) The effective mentor: a model for student centred learning in clinical practice. Nursing Times Research 1(2), 120-1323

Spouse J (1998a) Scaffolding student learning in clinical practice. Nurse Education Today 18, 259266

Spouse J (1998b) Learning to nurse through legitimate peripheral participation. Nurse Education Today 18, 345-351

Spouse J \& Redfern L (2000). Successful supervision in health care practice. Oxford: Blackwell Sciences

United Kingdom Central Council (1999) Fitness for Practice. The UKCC Commission for Nursing \& Midwifery Education. UKCC: London

Varpalotai A (1987) The hidden curriculum in leisure: an analysis of girls' sports subculture.

Women's Studies International Forum 411-422

Watson N (2001). Mentoring today - the students' views. An investigative case study of preregistration nursing students' experiences and perceptions of mentoring in one theory/practice module of the Common Foundation Programme on a Project 2000 course. Journal of Advanced Nursing 29(1), 254-262

Watson S (2000) Mentor preparation: reasons for undertaking the course and expectations of the candidates. Nurse Education Today 24, 30-40

[1] At several points during the participant observation, it was necessary for the researcher to intervene to ensure the safety of a patient. 